\title{
A Study on ESL Teachers' Intercultural Communication Competence
}

\author{
Yechun Zhang ${ }^{1}$ \\ ${ }^{1}$ School of Foreign Languages, Inner Mongolia University for Nationalities, Tongliao, China \\ Corresponding: Yechun Zhang, School of Foreign Languages, Inner Mongolia University for Nationalities, \\ Tongliao, China. Tel: 86-139-475-56792. E-mail: wyzhangyechun@126.com
}

\author{
Received: September 24, 2017 Accepted: October 24, 2017 Online Published: October 26, 2017 \\ doi: 10.5539/elt.v10n11p229 URL: http://doi.org/10.5539/elt.v10n11p229
}

\begin{abstract}
Intercultural Communication Competence (ICC) is the absolute necessity for talents in the 21 st century. Meanwhile, the development of ICC competence has already become a new teaching concept, which will penetrate in all aspects of language teaching activities. Indeed, to facilitate language learners to develop ICC, language teachers, especially those teaching English as Second Language (ESL), should first be competent intercultural communicators with great confidence and sufficient experience.

The study is undertaken to discover real picture of the ESL teachers' ICC competence by measuring their individual system, episodic system, and relational system. Most ESL teachers under the test are strong in their individual system in that they are highly proficient in English, and they have a good deposit of cultural and linguistic knowledge in target language. In this case, they are mostly likely to achieve communication effectiveness in intercultural communication. Nevertheless, they don't have well-built episodic system and relational system. This is largely due to the facts that they haven't experienced varying intercultural contexts, and the interpersonal relations with foreigners are inclined to be simple. All these factors contribute to ESL teachers' incompetence in accomplishing different tasks in intercultural communication, as well as in intercultural education. Therefore, ESL teachers should improve their ICC through real intercultural practices. Besides, the study also tests statistical significance between ICC and overseas experience, and the significance between ICC and frequency of contact with foreigners.
\end{abstract}

Keywords: intercultural communication competence, ESL teachers, individual system, episodic system, relational system

\section{Introduction}

Just as Fantini (1995) has said, to develop Intercultural Communication Competence has become a shared goal among most researchers and educators in intercultural and language field. Learning foreign language is no longer about knowing how to use language for the purpose of speaking and reading, but about knowing how to communicate with people who have different cultural identities. As a consequence, how to help English learners to develop their intercultural communication competence and what are the specific objectives to nurture ICC competence have aroused interests among researchers and teachers in foreign language education.

Some educators believe that development of ICC in foreign language classroom is a continual process, which involves paying attention to three levels of intercultural teaching objectives and criteria (Zhang, 2007). The first level is related to knowledge including linguistic awareness, cultural-general awareness, language ability of the target culture, culture knowledge of the target country. The second level is germane with competence containing communicative competence, abilities of using verbal and non-verbal messages, socio-cultural competence, and communication strategies. The third level is closely linked to attitude which is about empathy in intercultural communication, and critical cultural awareness. The series of teaching objectives tell that the behavioral, cognitive and emotional levels of ICC framework have been successfully employed into foreign language teaching. And there are more waiting to be accomplished with the joint efforts of both foreign language educators and intercultural scholars.

Since ICC competence has become a widely discussed topic both inside and outside the classroom where English is taught as Second Language, more and more ESL teachers in foreign language education have realized they need to devote more efforts so as to facilitate language learners to develop their intercultural communication competence. When they looked back in their past teaching experiences, they suddenly found that they fell short 
in resources and experiences in intercultural communication competence, especially personal experience in intercultural interactions, which are valuable input to elicit more revelations in teaching methodology. They think if they are competent communicators in intercultural communication, they will feel very confident when they talk about how to be a competent communicator to their junior learners, who are so inexperienced in intercultural communication, even at the scratching level. Therefore it is quite a necessity to examine the current situation among all ESL teachers on intercultural communication competence. How much they have implemented this new concept into their teaching? How competent they are when they communicate with people from other cultures? Are they fully aware of the knowledge, motivation, and skills needed for effective communication? Do they have enough resources and support for the education system to develop their intercultural communication competence as one aspect of professional development? All these questions are waiting to be answered with strenuous efforts in the area of intercultural communication research.

It is a conventional wisdom that the improvement of ICC for students through ESL teaching is strongly correlated the teachers' ICC competence. Succinctly, their experience in intercultural communication will greatly affect their perception of ICC, their knowledge in intercultural communication, and their way to apply teaching methodologies to conduct intercultural education. That is why to develop and evaluate teachers' ICC competence is more important than to implement ICC concept in ESL classroom. Competence in intercultural education is not an extra facet of teachers' professional development but should become integral part of that profession (Leeman \& Ledoux, 2003). If all ESL teachers not only have a good command of language, and are also capable to communicate with different people with various cultural backgrounds and communication contexts, it will not be too far for college students to improve their ICC competence in a reasonable way. On the contrary, if ESL teachers are poorly equipped in their understanding and skills of intercultural communication, not to mention the purpose to help student to improve ICC competence. In a word, to develop and further improve ESL teachers' ICC has become current in the agenda of ESL teachers' professional development and important ingredient in teachers' intercultural training, since most ESL teachers are language learners in the same sense with other learners.

\subsection{ESL Teachers and the Practice of Intercultural Education}

Since the goal of intercultural language teaching is to improve learners' ICC competence, as well as their awareness of intercultural communication. If possible, educators hope to train learners' ability to think critically in intercultural contacts, and use tolerant attitude to perceive the cultural differences. At the same time, learners are devoid of Ethnocentrism and prejudice when encountering different cultures. This high goal imposes a great challenge on most ESL teachers. Generally speaking, this requires ESL teachers to prepare themselves in three aspects (Zhang, 2007).

First, they should have sufficient intercultural knowledge. They know basic cultural knowledge, put it more precisely, basic concepts, components, characteristics of culture and its influence in a given society or individual. They master concrete knowledge for specific cultures, not only in cultures of target language, but also learning the culture of one's home country, as well as cultures of other countries and groups. They understand the interactions among language, culture and the society, specially the conditions in countries of the target language, in which English is spoken under different cultural contexts.

Second, ESL teachers should have these following abilities. They can communicate with others in English in and outside the classroom, other intercultural occasions in particular. They can make full use of the teaching materials and other authentic language materials to teach cultures and guide learners to concern about cultural issues, so as to stimulate their thinking in this regard. They are apt to design teaching and organize the class sections with inspiring activities, which can put learners' personal experiences with the cultural ideas given in the textbooks together. They are capable of using multiple teaching methods and approaches, in order to impart the cultural knowledge and communicative skills in an all-round way. They can integrate the language teaching with the culture teaching in a sound way. And through carefully selected learning materials, they design relevant activities which will improve language proficiency as well as their intercultural communication competence.

Third, ESL teachers have the following emotional qualities. They are brave enough to face up with the challenge in developing learners' ICC in the classroom, and put in efforts to innovate teaching methods. They are willing to be like moderate learners to study and dig into the knowledge of the foreign cultures, and to reflect on the culture of the home country, as well as to retrospect on thinking patterns of their own culture and the behaviors of themselves. They are willing to share with the learners their intercultural experience and learning experience in intercultural communication, even though they have ever experienced failures intercultural interactions. They show respect to their students and they don't make bold and hurried judgments on different cultural ideas and 
behaviors.

From the above requirements on ESL teachers, we can find out that developing teachers' ICC is the priority for intercultural education in language class.

\subsection{Current Barriers on ESL Teachers' ICC Development}

ESL teachers' professional development is essential in foreign language education, because the better teachers' individual qualities, the better effects the language classroom has. ESL teachers' knowledge base consists of the linguistic knowledge, teaching experiences, knowledge of applied linguistics, and statistics, knowledge of second language acquisition, and ability to integrate knowledge with practice, and abundant individual knowledge. Teachers feel inadequate in their individual knowledge and their ability to integrate knowledge with practice. Because they don't have enough opportunities to accumulate first hand experience, especially intercultural experiences. This fact is also indicated in the investigation on the needs of EFL teacher development in Chinese Universities (Zhuang, 2006). Her nationwide survey showed that $58 \%$ of the tested teachers are in urgent need to receive professional training to develop them; they think the main reason impeding their teaching performance is lack of training opportunities. And 47\% of ESL teachers hope they could get opportunities to study overseas, and $32 \%$ of these teachers hope they could receive professional training through visiting other universities, online learning, and workshops during summer and winter holidays. From these statistical facts, it is quite apparent that ESL teachers need develop themselves so as to meet the teaching requirements. Teaching embodies the four critical elements of a profession including knowledge base, quality control, resources, and conditions of practice. As essential component of professional quality, intercultural communication competence is in the state of underdevelopment. This condition should be improved immediately with the pace of education reform in the field of foreign language teaching. In fact, there are several problems which act as the stumbling blocks in ESL teachers' ICC development. First, ESL teachers are heavy workload in teaching so that they don't have time to enrich their knowledge and skills in intercultural communication. Second, they don't have clear guidelines by which they could develop their ICC in a gradual manner and knowing what is needed for their teaching. Third, until now there isn't a mandatory requirement for educators and teaching management leaders in universities and colleges to conduct intercultural trainings among teachers. Fourth, the opportunities to study overseas are too limited compared with majority of ESL teachers.

Although there are many barriers to overcomes, development of ESL teachers' ICC competence has become a necessity for most teachers in foreign language teaching.

\subsection{Hypothesis on ESL Teachers' ICC Competence}

In order to get a better view on ESL teachers' ICC competence, and delineate the strength and weakness of the individual, episodic and relational systems in this sub-cultural group, four hypotheses are established as the following,

Hypothesis One: ESL teachers are confident in dealing with intercultural communication. It will increase their motivation to contact with people from other cultures. They are less competent in Episodic System (Episodic competence) and their Rational System (Relational or Interpersonal competence). Hypothesis Two: Overseas experience makes teachers more competent communicators in intercultural communication. Hypothesis Three: Frequency of contact with foreigners is correlated with the level of competence. (Teachers who contact with foreigners often will have better scores). Hypothesis Four: Teachers' competence is mainly in the educational context and lacks goal-oriented communication.

\section{ESL Teachers' ICC Competence}

The most unexpected finding in this study is that confidence and efficacy beliefs, which are subjected to motivation in individual system, have relatively low scores among tested ESL teachers. More than half of teachers in the test think that they are not confident enough to take first step to meet new foreign friends. And roughly the same majority doesn't feel quite certain that they can build constructive relationship with foreigners. Some of the teachers are not confident to cooperate well with the foreign counterparts. This result is casting doubts on whether or not ESL teachers are fully ready for challenges in intercultural communication, because there is a clear correlation between motivation and confidence as well as efficacy beliefs (Spitzberg, 2000). The increase in confidence and efficacy beliefs leads to the increase of motivation in intercultural communication. He says that confidence result from several individual experiences and tendencies, such as anxiety in meeting strangers in home culture. Furthermore, if the person is not familiar with a given type of the situation, they feel lack of confidence. Sometimes, some situations carry more significant implications and are more difficult to manage than other situations; the person will lose much in confidence. He also asserts that efficacy beliefs are 
self-perceptions of ability to perform a given set of behaviors. Basically, the more the person believes that he or she is able to engage in a set of valued or positive actions, the more prone that person is to accomplish his estimation. He said that efficacy beliefs are therefore usually task-specific.

The second finding significant to ESL teachers is that they perform relatively unsatisfying in episodic system. To put is in the other way, they lack episodic competence (Spitzberg, 2000). Episodic competence is mirrored by the impression of communicator's interactants and related to sub-constructs like readiness of individual system, contextual obstructions, which refers to how difficult the social contexts are, and positive outcomes consistently achieved from the communication, and the realization of the positive expectation from the interactants in host culture. From the finding that ESL teachers are not confident enough to deal with intercultural challenges, it can be assumed that individual system, especially motivation has already imposes impact on episodic competence in a negative fashion, or it is the other way around. Due to ESL teachers' limited intercultural experience in different social contexts which has been proven in other findings, confidence does not fully come into being. According to the results from the Hypothesis four, it can be concluded not gaining enough rewarding outcomes from intercultural communication is a strong argument in poor performance in episodic competence.

As one of the vantage points in this research, relational competence is another important aspect of ICC competence. Spitzberg believes that relational system (relational competence) is chiefly a cumulative outcome of effect from individual and episodic systems, and its sub-constructs are mutual attraction, mutual trust, social support, and social network integration. The last two elements in relational competence are tested in the research, and others are put aside for they are not easily measured and changed according to individual cases and preferences of personality traits. Here the focus is put on the former two sub-constructs. Assess to social support is important for individuals to cope with problems and stresses in life. Moreover, as relational network integration increases, relational competence increases. After examining the ESL teachers' current conditions, it can be presumed that foreigners for most ESL teachers are not the major source of their social support, especially when they have some personal problems they are not going to turn to foreigners for help. Even if foreigners help our Chinese ESL teachers solve some psychological difficulties, the impact is limited compared with Chinese friends and family members. Only those who stayed in foreign countries found social support is so critical in their life when they were overseas. At that moment, social support is inevitable, and host countries nationals are the main source of the social support for these ESL teachers. Nevertheless, generally the limited intercultural experience may impede ESL teachers to get more social support from their foreign acquaintances.

\section{Overseas Experience and ICC Competence}

From the second hypothesis, it can be learned that ESL who have oversea experience is more competent than others who don't have oversea experience. This result also proves that there is a significant relationship between intercultural experience and intercultural communication competence, since staying in the host country is main kind of intercultural experience. This international travel should improve intercultural knowledge, which is gained from a more in-depth immersion in a new environment (Fisher \& Price, 1991). Billingmeier and Forman (1975) demonstrate extended experience outside of one's own culture has a lasting effect on the individual's intercultural knowledge and overall view of diverse cultures. Anther aspect that oversea experience brings to a person is the process of adaptation in anther culture which will produce a series of psychological changes, which produce the main constructs of intercultural communication competence and enhanced cultural awareness, and intercultural sensitivity.

The process of the intercultural adaptation plays an important role to form intercultural communication competence. In a broader sense, intercultural adaptation refers to the process of becoming competent to meet the demands of the new cultural environment (Kim, 1991). It deals with how sojourners experience distress caused by mismatches or incompatibility between the host culture and the home culture, as well as challenges to survive in intercultural world. Hammer, Gudykunst, and Wiseman (1978) propose three behavior dimensions associated with intercultural effectiveness including the ability to deal with psychological stress, the ability to communicate effectively and the ability to establish meaningful interpersonal relationships. They further explain each of the three abilities. They contend that psychological stress in intercultural communication means frustration, stress, anxiety, pressure to conform, social alienation, financial difficulties, and interpersonal conflicts, which are not commonly seen in domestic environment or educational settings due to the interactions with people from different cultural backgrounds.

What can oversea experience bring to the intellectual sojourners? Most of them will face intercultural challenges at all level of the host country. There are six dimensions (Furnham and Bocher, 1982) in intercultural challenges. First, the formal relations dimension deals with the understanding of rules and customs of host culture, especially 
when the focus of sojourners is on social interaction. Second, the relationship management dimension involves the abilities to initiate friendships and to understand host nationals. Third, the public ritual dimension refers to the ability to adapt to public facilities of host culture. Fourth, the initiating contact dimension concerns the initiating and maintaining of contacts with host nationals. Fifth, the public decision-making dimension involves making choices regarding various public issues. Finally, the assertiveness dimension deals with the cases of hostility and rudeness.

Due to the challenges, some competences oriented to changes occur. In domestic setting, knowledge of the social customs and social rules are acquired in the process of socialization in the course of the formal education, and knowledge on these aspects remain in subconscious level, and can be automatically recalled from the memory for the instant needs, while in a foreign environment, the reservoir of social knowledge is usually mismatched with what one can dispose either from the home culture or from other indirect sources, such as mess media or intellectual documents. No matter how knowledgeable the person is on the host cultural, what the person knows already will be challenged and reevaluated in the new environment. Most often, oversea experience will change some old assumptions and clarify some doubts held in dated knowledge. The new input on social rules and customs will direct one's behaviors in different social contexts, such as weddings and funerals, which are hardly witnessed in domestic settings.

Relationship management will happen on two directions when staying overseas. One leads to communication at social level where sojourners have to contact with people working in public institutions. Both social skills and language skills are need to meet social expectations which impose great stress on sojourners as well as opportunities to learn how to function normally in another culture. Later these life experiences will either enhance self-esteem or provide powerful knowledge base for future contact with people from the host country. The other direction leads to more micro communication level at which by talking to different people at all walks of life, a comprehensive view is gained to understanding host nationals at a new level, which is similar to what one has experienced at home country. In this way, the sojourners have obtained intercultural communication competence in terms of communication skills and cultural awareness (Chen, 1989). This is true for the third and fourth dimensions in intercultural challenges. Especially using public facilities is once-in-a-lifetime opportunity to understand the host culture at the conventional and institutional levels. The fifth challenge is public decision making and sixth challenge is assertiveness. Sojourners are no longer spectators of national movements in host country, but act as witnesses either participant of the public activities, and to certain extent failing to behave neutral in the given situation, such as racial and ethnical hatred. Involvement in the social disputes is sometimes unavoidable. Real life experience with strong personal preferences and stands will ultimately change a person's world view and provoke intense cultural awareness and intercultural sensitivity towards both host and home cultures.

To summarize, overseas experience will significantly elevate skills, knowledge, episodic and relational competence in intercultural communication.

\section{Frequency of Contact and ICC Competence}

The presumption that ESL teachers who contact frequently on the weekly basis are more competent in intercultural communication than who communicate with foreigner less frequently has been conformed by the statistical measurement. The implication of the this comparison is quite clear to perceive, that the more a person gets into touch with foreigners, the more likely he or she obtains competence in intercultural communication. Since ICC competence is a growing process along with a person's growing intercultural cultural experience. This statistical result indicates that over half the ESL teachers don't practice their communication skills regularly, and many seldom have any contact with foreign people. These facts will severely impede the growth of ICC among ESL teachers, whose cognition on ICC will affect their positively affect the intercultural education.

Another significant function of contact frequency on ICC is that communication skills can be improved in terms of conversation management, cultural awareness, and interpersonal relation development. Communication is for exchanging friendly emotions and sharing happy time which are realized through talking or playing with each others. Verbal message plays an important role in building relations. Conversation is commonplace, mostly bridging cultural differences. ESL teachers usually can get chance to practice conversation management in intercultural setting, which entails seeking interpersonal harmony, responsiveness in conversation, self-monitoring, and self-disclosure appropriate to the language targeted culture ( Dodd, 1988). These imply turn-taking and ability to adapt interaction goals and behaviors to others, keeping cultural rules and practicing etiquettes. Cultural awareness (Chen, 1989) is also another important construct in ICC competence, which refers to understanding the conventions of the host culture that affect how people think and behave. The thinking 
pattern in each culture is different from others; therefore knowing the thinking patterns of other cultures enables the communicator to realize effective communication. Both sources emphasize the importance of the cultural knowledge for effective communication. Cultural awareness requires understanding the "cultural map", by which people from another culture won't get lost in the host culture. Awareness of the culture means to catch the "culture theme", which refers to the thread that goes through the culture and organizes a culture as a recognizable system. Consequently having conversations with foreigners will improve cultural knowledge in the host culture and understand the thinking pattern of people in that culture.

\section{Conclusion}

ESL teachers are just one group who are shouldering the responsibility to promote the intercultural communication through education. This make this research extremely meaningful in investigation of ESL teachers' intercultural communication competence, which will to certain extent contribute the improvement of ESL teachers professional development, as well as innovate teachers' concept on relationship between language teaching and intercultural communication. And this will make some profoundly grass-root changes in language teaching with strong scent of intercultural education.

For most ESL teachers, without leaving their current teaching positions, the best choice to gain intercultural communication competence is through educational intervention, intercultural training in particular. Programs designed for intercultural training are developed to improve interaction effectiveness by increasing the familiarity with customs of the host culture, by understanding cultural differences, and by using of highly proficient language skills. Intercultural training demands of an awareness of both human differences and similarities. Professionals in business and education, especially ESL teachers, are called upon to infuse their practices with an awareness of their own personal and cultural background and their experiences in intercultural communication. For them, both a positive self-perception in intercultural communication and accumulation of intercultural understanding are needed, so as to improve intercultural communication competence. Actually some scholars (Hou, 2003; Xia, 2004) in China have already stressed the importance of intercultural training in develop ESL teachers' ICC through various methods. For example, ESL teachers act as trainees to study in other countries in short-term programs. And intercultural training programs use internet and multimedia technology in their program to improve ESL teachers' intercultural communication competence. All these efforts will contribute to development of competence in intercultural communication.

\section{Acknowledgement}

Supported by Inner Mongolia Social Science. Project Name: A Study on the Intercultural Communication Competence of Teachers' in the Universities for Nationalities. Project Number: GJB16115.

\section{References}

Billingmeirer, R. T., \& Forman, D. (1975). Gottigen in retrospect. International Review of Education.

Chen, G. M. (1989). Relationships of the dimensions of intercultural communication competence. Communication Quarterly, 37(2), 118-133. https://doi.org/10.1080/01463378909385533

Dodd, C. H. (1988). Dynamics of Intercultural Communication. Boston, MA: McGraw Hill.

Fantini, A. E. (1995). Introduction-language, culture and world view: exploring the nexus. In International Journal of Intercultural Relations, 19(2), 143-153. https://doi.org/10.1016/0147-1767(95)00025-7

Fisher, R. J., \& Price, L. L. (1991). International pleasure travel motivations and post-vacation cultural attitude change. Journal of Leisure Research.

Furman, A., \&Bochner, S. (1982). Social difficulty in a foreign culture: an empirical analysis of culture shock. In S. Bochner (Ed.).

Gudykunst, W. B., Hammer, M. R., \& Wiseman, R. L. (1977). An analysis of an integrated approach to cross-cultural training. International Journals of Intercultural Relations, 1(2), 99-110. https://doi.org/10.1016/0147-1767(77)90045-1

Kim, Y. Y. (1991). Intercultural communication competence: A systems-theoretic view. In S. Ting-Toomey, \& F. Korzenny (Eds.).

Leeman, Y., \& Ledoux, G. (2003). Preparing teachers for intercultural education. Teaching Education, 14(3), 279-192. https://doi.org/10.1080/1047621032000135186

Spitzberg, B. H. (2000). A model of intercultural communication competence. In Samovar, L. \& R. Porter (Eds.).

Hou, R. J. (2003). Culitvation of Intercultural Communicative Skill for English Teachers in Higher Education 
Intitution. Heilongjiang: Heilongjiang Researches on Higher Education.

Zhang, H. L. (2007). Intercultural Approach to Foreign Language Teaching. Shanghai: Shanghai Foreign Language Education Press.

Zhuang, E. P. (2006). Intercultural Competence: an Absolute Necessity for Talents in 21st Century, from the Summary of 2006 International Seminar on Intercultural Communication, Beijing: Foreign Language World.

\section{Copyrights}

Copyright for this article is retained by the author(s), with first publication rights granted to the journal.

This is an open-access article distributed under the terms and conditions of the Creative Commons Attribution license (http://creativecommons.org/licenses/by/4.0/). 